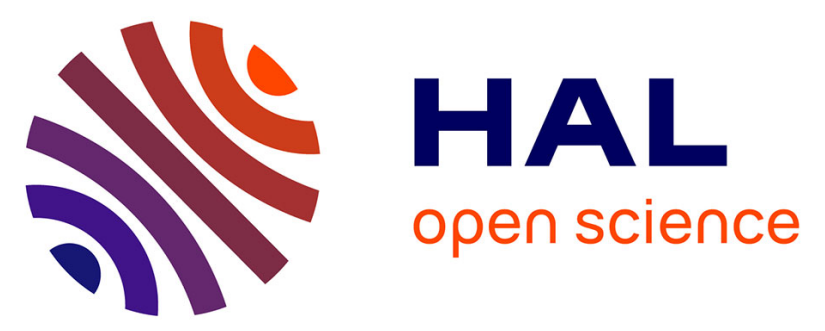

\title{
High estrogen receptor expression in early breast cancer: chemotherapy needed to improve RFS?
}

\author{
A. C. Regierer, R. Wolters, C. Kurzeder, A. Wöckel, I. Novopashenny, K. \\ Possinger, M. B. Wischnewsky, R. Kreienberg
}

\section{- To cite this version:}

A. C. Regierer, R. Wolters, C. Kurzeder, A. Wöckel, I. Novopashenny, et al.. High estrogen receptor expression in early breast cancer: chemotherapy needed to improve RFS?. Breast Cancer Research and Treatment, 2011, 128 (1), pp.273-281. 10.1007/s10549-010-1334-9 . hal-00615395

\section{HAL Id: hal-00615395 \\ https://hal.science/hal-00615395}

Submitted on 19 Aug 2011

HAL is a multi-disciplinary open access archive for the deposit and dissemination of scientific research documents, whether they are published or not. The documents may come from teaching and research institutions in France or abroad, or from public or private research centers.
L'archive ouverte pluridisciplinaire HAL, est destinée au dépôt et à la diffusion de documents scientifiques de niveau recherche, publiés ou non, émanant des établissements d'enseignement et de recherche français ou étrangers, des laboratoires publics ou privés. 


\section{Original article}

High estrogen receptor expression in early breast cancer: Chemotherapy needed to improve RFS?
A. C. Regierer ${ }^{1,2^{\star}}$, R. Wolters ${ }^{1 *}$, C. Kurzeder ${ }^{3}$, A. Wöckel ${ }^{3}$,

I. Novopashenny ${ }^{1}$, K. Possinger ${ }^{2}$, M. B. Wischnewsky ${ }^{1}$, R. Kreienberg ${ }^{3}$

${ }^{1}$ Faculty of Mathematics and Computer Science, University Bremen, Bremen, Germany, ${ }^{2}$ Department of Oncology and Hematology, Charité Universitätsmedizin Berlin, Berlin, Germany, ${ }^{3}$ Department of Gynecology and Obstetrics, Clinical Hospital of the University of Ulm, Ulm, Germany

* Both authors contributed equally to this manuscript.

Corresponding author:

Anne C. Regierer, MD, Department of Oncology and Hematology, Charité Universitätsmedizin Berlin, Charitéplatz 1, 10117 Berlin, Germany

Tel.: +49-30-450-513002

Fax: +49-30-450-513952

Email: anne.regierer@charite.de 


\section{Abstract}

Background:

One of the most controversial questions in early breast cancer treatment is the need of chemotherapy in patients with estrogen receptor positive disease. Therefore we analyzed a group of patients with high ER expression to scrutinize the role of chemotherapy in this situation. To gauge the effect of chemotherapy on RFS three treatment modalities were compared: endocrine treatment only, chemoendocrine treatment, and chemotherapy.

Patients and methods:

3971 breast cancer patients whose treatment modalities as well as ER level were known, were included in this retrospective analysis. Their level of ER expression was documented as IRS. A high ER group was defined as ER IRS $\geq 9$; primary endpoint was RFS.

Results:

RFS was associated with ER, with the best outcome for strong and the worst result for negative expression. Adjusted to NPI, RFS did not differ between the treatment cohorts of endocrine treatment and chemoendocrine treatment $(p=0.828)$ in the high ER group. Patients with chemotherapy alone fared significantly worse $(p=0.003)$. Even in high risk patients (according to NPI) the chemoendocrine and the endocrine treatment only groups did not differ significantly $(\mathrm{HR}=1.15 ; 95 \% \mathrm{Cl}(0.56-2.34), \mathrm{p}=0.709)$. Omission of endocrine treatment led to significantly worse outcome $(p=0.013)$.

Conclusions:

RFS was significantly longer in patients with high ER expression than with weak or no ER expression. In the high expression group, there was no significant 
difference in RFS between endocrine treatment only and chemoendocrine therapy - even in high risk patients, for whom chemoendocrine treatment is routinely indicated. It seems insufficient for high ER patients to only consider tumor size, nodal status, and grading in order to decide which patient will benefit from adding chemotherapy to endocrine treatment. 
Key words:

Adjuvant chemotherapy, early breast cancer, endocrine treatment, estrogen receptor, immunoreactive score, quantitative hormone receptor expression 


\section{Introduction}

The St Gallen consensus meeting in 2009 has proposed a treatment selection algorithm for the management of early breast cancer which is fundamentally different from that used in previous years [1]. The indications for the three treatment modalities - endocrine treatment (ET), anti-HER2 therapy and chemotherapy - are based on different criteria which need to be analysed separately for individual treatment decisions. One of the most urgent questions concerns the need of chemotherapy in estrogen receptor (ER) positive diseases [2-4].

The additional benefit of chemotherapy on top of ET is controversial and may be influenced by a variety of factors, the most important of which is the endocrine responsiveness of the tumor. The definition of the categories "highly endocrine responsive", "incompletely endocrine responsive", and "endocrine nonresponsive" relies mainly on the level of ER and PgR expression, but other factors such as grading, HER2/neu status, proliferation index, and levels of UPA/PAI1 also play an important role [1]. The cut point between the ER and $\mathrm{PgR}$ expression levels needed to define high endocrine responsiveness was according to St Gallen $200950 \%$ of positive tumor cells [1], a value chosen more or less arbitrarily.

We hypothesize that patients with highly endocrine responsive tumors may have only a minor or even no additional benefit by adding chemotherapy to ET. Retrospective analyses of prospective randomised trials [5-7], in which the benefit of chemotherapy decreased with increasing levels of ER/PgR expression have served to a high degree to support our hypothesis. In order to further address this issue we analyzed a group of patients with high ER expression as to the influence of the different treatment modalities of ET alone 
versus chemoendocrine therapy versus chemotherapy alone. Our cohort including 3971 patients - is part of the BRENDA project (breast cancer care under evidence-based guidelines), a large cohort study funded by the German Federal Ministry of Education and Research (BMBF).

Obviously retrospective observational studies have methodological caveats, the main problem being a selection or information bias and known as well as possibly unknown confounding factors [8]. While results are irreparably compromised by selection and information biases, confounding factors can be corrected by e.g. multivariate adjustment models. However, analysing "real life" cohorts has the advantage that effectiveness is tested in everyday practice with relatively unselected participants and under flexible conditions, whereas explanatory prospective randomized trials test efficacy in a research setting with highly selected participants and under highly controlled conditions $[9,10]$. We therefore believe that our results, since they have been derived from a large cohort study will help to answer the crucial question which ER positive patient will benefit from adding chemotherapy to ET. 


\section{Patients and Methods}

\section{Study Design}

Within the BRENDA project (breast cancer care under evidence-based guidelines) funded by the BMBF a large clinical cancer register was established. Patients were diagnosed between 1992 and 2005 at the Department of Obstetrics and Gynecology, University of UIm Medical Center, and affiliated breast cancer centers. This analysis included 3971 early breast cancer patients whose treatment modalities as well as ER immunoreactive score (IRS) levels were known. Baseline characteristics are shown in table 2.

The level of HR expression was documented as IRS. IRS is the product of a proportion score and an intensity score (table 1) with a range of 0-12. A high ER group was defined as $E R I R S \geq 9$.

\section{Statistical analysis}

The primary endpoint is recurrence free survival (RFS). Nominally scaled variables were tabulated in contingency tables and tested for differences in frequency distribution. Variables for location and variance were calculated whenever ordinally scaled and intervally scaled continuous variables were involved. For each group we calculated numbers of cases, means, standard deviations, standard error of mean, minimum, maximum, 95\% confidence interval $[\mathrm{Cl}]$ for the mean, and medians. Levene's test for homogeneity of variance, analysis-of-variance tables and robust tests of the equality of means (medians) were similarly used. Normal distribution was tested using the Kolmogorov-Smirnov (K-S) goodness-of-fit test. In addition we also used the Anderson-Darling test and the Cramer-Smirnov-Von-Mises test, a modification of the K-S test giving more weight to the tails of the distribution. Standard survival analysis using a Kaplan-Meier approach was performed for assessing 
RFS. Logrank test was used to provide a formal statistical assessment of the differences between treatment arms. Cox proportional hazards model was used to estimate the hazard ratio and confidence intervals. Comparisons of categorical variables between groups were made by using $x^{2}$ tests.

In order to improve the internal validity we checked for selection bias, information bias and confounding factors. Results were adjusted by taking into account all measurable confounders and inhomogeneities in baseline status in the form of multivariate adjustment using the Cox proportional hazard regression method. 


\section{Results}

We found the following distribution of levels of estrogen expression according to IRS: $27 \%$ negative, $7 \%$ weak, $26 \%$ intermediate, and $40 \%$ strong.

As described in table 2, the ER groups differ significantly in the clinical risk factors age, menopausal status, tumor size, nodal status, grading, and HER2/neu.

\section{Recurrence free survival according to ER groups}

As expected, RFS was associated with ER, with best outcome for strong and worst for negative expression (fig. 1). RFS for weak and negative expressions in relation to high expression was significantly worse (weak expression: $H R=1.85$; 95\% Cl (1.35-2.54), $p<0.001$; negative expression: $\mathrm{HR}=2.29$; $95 \% \mathrm{Cl}(1.86-$ 2.82), $\mathrm{p}<0.001$; using logrank test). On the other hand, RFS for moderate in relation to high expression was not significantly worse (HR=1.23; $95 \% \mathrm{Cl}(0.97-$ 1.56), $p=0.084)$.

Outcome for patients with high ER expression according to adjuvant systemic treatment

We analysed the subgroup of patients with high ER expression $(E R+, I R S \geq 9$ : $\mathrm{n}=1595(40.2 \%))$ with regard to the treatment modalities of chemoendocrine therapy (chemotherapy followed by ET) $(n=383(24.0 \%))$, ET alone $(n=892$ $(55.9 \%))$ and chemotherapy alone $(n=51(3.2 \%)) .269$ pts obtained either no or an unknown drug therapy.

Without adjustment to risk factors, RFS was significantly longer in patients with ET alone compared to chemoendocrine and chemotherapy alone (chemoendocrine vs. $\mathrm{ET}: \mathrm{HR}=1.74 ; \quad 95 \% \quad \mathrm{Cl} \quad(1.13-2.68), \quad \mathrm{p}=0.012$; chemotherapy alone vs. ET: HR=3.52; $95 \% \mathrm{Cl}(1.95-6.35), \mathrm{p}<0.001)$ (fig. $2 \mathrm{~A})$. After adjustment to standard prognostic factors (Nottingham prognostic index 
(NPI), menopausal status, and HER2/neu), RFS did not differ between the groups with ET and chemoendocrine treatment $(\mathrm{HR}=1.05 ; 95 \% \mathrm{Cl}(0.67-1.65)$, $p=0.828)$. However, patients treated with chemotherapy alone still fared significantly worse $(\mathrm{HR}=2.48 ; 95 \% \mathrm{Cl}(1.36-4.51), \mathrm{p}=0.003)$ (fig. 2B).

The significant differences between the curves without and with adjustment reflect the fact that, due to the retrospective nature of the analysis, the treatment modality depends on the risk factors. Therefore these factors are not balanced between the treatment groups; i.e. patients with more risk factors are more likely to have received chemotherapy than patients with less risk factors. The correlation that chemotherapy seems not to add any benefit to ET was shown for post- and premenopausal patients to a similar extent.

\section{Nottingham prognostic index (NPI)}

The high ER group was further analysed regarding NPI, which combines grading, nodal status, and tumor size. As expected, RFS curves differ significantly between the groups of low, intermediate, and high risk (intermediate vs. low: $\mathrm{HR}=2.33 ; 95 \% \mathrm{Cl}$ (1.41-3.84), $\mathrm{p}=0.001$; high vs. low: $H R=8.12 ; 95 \% \mathrm{Cl}(4.95-13.32), \mathrm{p}<0.001)$ (fig. 3A).

We then analysed the NPI-groups separately according to treatment modalities. Even in the high risk group, ET alone showed the longest RFS. Chemoendocrine treatment did not differ significantly, and, as expected, the omission of ET led to significantly worse results (chemoendocrine vs. ET: HR=1.15; 95\% Cl (0.56-2.34), $\mathrm{p}=0.709$; chemo vs. $\mathrm{ET}$ : $\mathrm{HR}=3.07 ; 95 \% \mathrm{Cl}$ (1.27-7.40), $\mathrm{p}=0.013$ ) (fig. 3B).

The correlation described above - i.e. that chemotherapy seems to add no further benefit in high ER expression - was also found in the low and intermediate NPI groups. 


\section{Influence of the type of endocrine therapy}

Tamoxifen or aromatase inhibitors were mainly used as ET. We included all patients who received aromatase inhibitors in this cohort, not distinguishing between upfront or sequential treatment and found no significant difference in the RFS of patients with high ER expression receiving either tamoxifen or aromatase inhibitors (data not shown).

\section{Influence of the type of chemotherapy}

Types of chemotherapy used in our cohort included mainly CMF, anthracycline or taxane containing regimens. Consequently we analysed the three main regimen types separately. CMF regimens were given to $25 \%, 49 \%$ received anthracycline containing regimens, and $26 \%$ taxane containing regimens. The survival curves showed the same pattern, regardless of the type of chemotherapy in the high ER group (see fig. 4) as was shown for chemotherapy as a whole cohort (fig. 2B). Thus fig. 4 - showing RFS for the high ER group stratified for ET, and taxane-endocrine treatment - can serve as an example for all chemotherapy groups. As described above in fig. 2B in which all chemotherapies are included, the RFS curves for ET only and taxane containing chemotherapy followed by ET are not separated. 


\section{Discussion}

It has by now been widely accepted that the merely dichotomous reporting of ER and/or PgR status as positive resp. negative is oversimplified and thus the categories of "highly endocrine responsive", "incompletely endocrine responsive", and "endocrine nonresponsive" have been introduced [11, 1]. Although their definition relies mainly on the level of ER and PgR expression, other factors such as grading, HER2/neu status, proliferation index, and levels of UPA/PAl1, also play an important role. Thus the controversy about which HR positive patient will benefit from adding chemotherapy to ET, so important in clinical practice, comes more and more into research focus, too. In this analysis we have tried to define the role of chemotherapy in a group of patients with high ER expression measured by classical immunohistological ways.

As previously described, we found an association between the level of HR expression and outcome in early breast cancer. ER status has been used for decades as a predictive marker for the response to ET in all clinical indications and for all commonly used endocrine substances [12-15]. A moderate prognostic value has been described previously in patients not receiving any type of systemic therapy [16].

In this analysis, we have focused on the population of patients with a high expression of ER. The definition of high HR expression is not uniform. The St Gallen experts stated that a count of $\geq 50 \%$ of positive tumor cells should be considered highly endocrine-responsive [1]. Other studies derived from the definition of the Allred-Score [17] have defined high expression as $\geq 33 \%$ of positive cells, and still others even as $\geq 80 \%$ [18].

The historically accepted scoring systems are using not only the percentage of positive cells but also staining intensity $[19,20]$. The Allred score, widely used in 
the USA, is calculated by summing staining intensity $(0-3)$ and the percentage score $(0-5)$ receiving values from $0-8$ [21]. The Remmele score, widely used in Germany, is calculated by multiplying staining intensity (0-3) and percentage score (0-4) receiving values from 0-12 [22, 23]. The Remmele Score has two major limitations. Due to the calculation by multiplication valid values are not continuous. This is not in accordance with the fact that HR expression is a continuous biological variable ranging from no expression in any tumor cell to high expression in all tumor cells. The second limitation of the score is that the interpretation was not used uniformly. In the original work neither a cut-off value to define positive vs. negative expression nor a definition of high expression was given [22]. As the interpretations of the results thus differ remarkably, we have used the most common classification (see table 1). An IRS of 9 and higher defining the group of high ER expression in this analysis corresponds to at least $50 \%$ positive cells with a strong staining intensity.

The impact of quantitative measurement of HR expression as a prognostic and predictive test was analysed in various settings [5, 24-28]. For example in adjuvant patients DFS was significantly longer in patients with high ER levels $(>10 \%$ positive cells) than in those with lower (1-10\%) and negative (absent) expression [24]. This was also shown in a subgroup of the ATAC-trial population, who showed a significant relationship between ER level and time to recurrence [25]. Paik et al [26] described a significant test for the interaction of tamoxifen treatment and ER expression indicating that quantitative ER expression predicts benefit from tamoxifen treatment. The largest benefits of tamoxifen were observed with high quantitative ER.

Elledge et al [17] described a significant positive correlation of increasing ER levels and outcome in tamoxifen treated patients with metastatic breast cancer. 
Conflicting results were described in a subgroup of patients from the PO25 trial comparing letrozole vs. tamoxifen in advanced breast cancer [29]. No correlation was found between the ER expression level and TTP, neither in letrozole nor in tamoxifen treated patients. However, there was a significant effect of PgR expression (negative vs low vs high) on TTP in both treatment arms.

Our finding that adding chemotherapy to tamoxifen in patients with high HR expression shows no additional benefit corresponds to findings by Viale et al [6]. Also retrospective analyses of adjuvant and neoadjuvant trials have shown a decreasing chemotherapy efficacy with increasing HR levels $[5,7]$.

In our patient population the group of patients with high expression of ER has not proved an additional benefit from adding chemotherapy to ET. This holds true for all risk groups according to NPI, even for high risk patients. To our knowledge all treatment guidelines recommend chemotherapy to NPI high risk patients. The recent St Gallen recommendations differentiate indications for chemoendocrine therapy in patients with ER positive, HER2 negative disease [1]. Certain clinicopathological features such as ER/PgR, grading, proliferation index, nodal status, peritumoral vascular invasion, and tumor size, which together define the categories of "highly endocrine responsive", "incompletely endocrine responsive", and "endocrine nonresponsive", need to be considered for treatment decisions. Our data supports this and might be used as additional information in the controversy over the need for chemotherapy in patients with high HR expression, even in high risk patients.

We also analysed the impact of the type of ET and of chemotherapy. We did not find a significant difference between tamoxifen and Al. For the chemotherapy groups we found the same RFS patterns regardless of the types of 
chemotherapy. Even for taxane containing regimens, which are widely recognised as the most potent chemotherapy regimens up to now [30, 31], we did not find an additional benefit compared to ET alone. This is contradictory to the findings that the risk reduction effect due to taxanes was almost identical in HR negative and positive patients $[2,18]$. Other adjuvant or preoperative studies however, have found significant differences in the extent of the chemotherapy effect according to HR [32-35].

Recently gene expression profiles have been developed to analyse the individual recurrence risk in order to individualise adjuvant breast cancer treatment [36-39]. For example, the 21-gene panel [40] includes mainly genes involved in tumor cell proliferation and hormonal response. The score was developed in node negative, tamoxifen-treated patients [40] to predict the recurrence risk in these low risk patients. Paik et al then showed that the recurrence score (RS) also predicts the likelihood of benefit from chemotherapy [41]. Patients with high-RS tumors (i.e. high risk of recurrence) had a large benefit from chemotherapy; patients with low-RS tumors derived minimal if any benefit from chemotherapy. Similar results have recently been published [4244].

There is a lively debate about the additional predictive value of these multi gene arrays to classical clinical, histopathological, and immunohistological parameters. It has been shown that the combination of classical parameters and RS has increased the prognostic power to define the risk of patients [43, 45]. We believe that the integration of quantitative HR expression into the treatment decision will help towards optimising this crucial decision.

Our data derives from a clinical cancer register and not from a trial population, with all the inherent advantages and disadvantages. The major problem is the 
presence of known and possibly unknown confounding factors affecting both treatment and outcome (cp. fig. $2 \mathrm{~A}$ and $2 \mathrm{~B}$ ). Therefore, in order to come as close as possible to the clinically most relevant subject-specific measure of treatment effect, we adjusted our results to the most important prognostic covariates. The three main reasons why we used covariate adjustment methods are the following: First, to correct for imbalances in baseline prognostic covariates; second, to increase power by modelling the variability in outcome explained by relationships with highly prognostic covariates, and third, to obtain treatment effect estimates that would be more closely relevant for individual patients than to an average population [46-48].

The interpretation of observational study data in regard to causality should be carried out with great caution [8]. The Hills criteria of causation (strength of association, consistency, specificity, temporality, biological gradient, biological plausibility, coherence with existing knowledge, evidence, and analogy) outline the minimal conditions needed to establish a causal relationship between two items. Since the Hills criteria of causation - even if met, as in our case - cannot bring indisputable evidence for or against a cause-and-effect hypothesis and none can be required as a sine qua non, we can only derive associations, and not causality, from our results.

We believe that reviewing the role of chemotherapy in ER high expressing patients is a very important issue, especially since this subgroup is the largest group of patients with HR positive diseases, representing approximately $40 \%$ of all breast cancer patients. Our findings of no significant difference between ET and chemoendocrine treatment in ER high expressing patients indicates that using the clinical routine parameters of tumor size, nodal status and grading is not sufficient for the crucial treatment decision of ET vs. chemoendocrine in 
these patients. Whether the recurrence score derived from multiple gene arrays or parameters like Ki-67 are helpful for this decision is open to further discussion. We are confident that further individualisation of adjuvant treatment by means of modern multi-gene arrays as well as classical clinical and histopathological methods will help to maximise efficacy and minimise unnecessary toxicity. 


\section{Funding}

This study has been supported by the German Federal Ministry of Education and Research (BMBF) (grant number: 01ZP0505). 


\section{References}

1. Goldhirsch A, Ingle JN, Gelber RD, et al (2009) Thresholds for therapies: highlights of the St Gallen International Expert Consensus on the primary therapy of early breast cancer 2009. Ann Oncol 20(8):1319-29

2. Montemurro F, Aglietta M (2009) Hormone receptor-positive early breast cancer: controversies in the use of adjuvant chemotherapy. Endocr Relat Cancer 16(4):1091-102

3. Hassett MJ, Hughes ME, Niland JC, et al (2008) Chemotherapy use for hormone receptor-positive, lymph node-negative breast cancer. J Clin Oncol 26(34):5553-60

4. Thürlimann B, Price K, Gelber RD, et al (2009) Is chemotherapy necessary for premenopausal women with lower-risk node-positive, endocrine responsive breast cancer? 10-year update of International Breast Cancer Study Group Trial 11-93 Breast Cancer Res Treat 113(1): 137-144

5. Pagani O, Gelber S, Simoncini E, et al (2009) International Breast Cancer Study Group. Is adjuvant chemotherapy of benefit for postmenopausal women who receive endocrine treatment for highly endocrine-responsive, node-positive breast cancer? International Breast Cancer Study Group Trials VII and 12-93. Breast Cancer Res Treat 116(3): 491-500

6. Viale G, Regan MM, Maiorano E, et al (2008) Chemoendocrine Compared With Endocrine Adjuvant Therapies for Node-Negative Breast Cancer: Predictive Value of Centrally Reviewed Expression of Estrogen and Progesterone Receptors-International Breast Cancer Study Group. J Clin Oncol 26(9):1404-10 
7. Colleoni M, Bagnardi V, Rotmensz N, et al (2008) Increasing steroid hormone receptors expression defines breast cancer subtypes non responsive to preoperative chemotherapy. Breast Cancer Res Treat $116(2): 359-69$

8. Grimes DA, Schulz KF (2002) Bias and causal associations in observational research. Lancet 359: 248-52

9. Booth CM, Tannock IF (2008) Reflections on Medical Oncology. Twentyfive Years of Clinical Trials in Oncology: Where Have We Come and Where Are We Going? J Clin Oncol 26:6-8

10. Haynes B (1999) Can It Work? Does It Work? Is It Worth It? The Testing of Healthcare Interventions Is Evolving. Brit Med J 7211: 652-653

11. Goldhirsch A, Wood WC, Gelber RD, et al (2007) 10th St. Gallen conference. Progress and promise: highlights of the international expert consensus on the primary therapy of early breast cancer 2007. Ann Oncol 18(7):1133-44

12. International Breast Cancer Study Group (IBCSG) (2002) Endocrine responsiveness and tailoring adjuvant therapy for postmenopausal lymph node-negative breast cancer: a randomized trial. J Natl Cancer Inst $94(14): 1054-65$

13. International Breast Cancer Study Group, Colleoni M, Gelber S, et al (2006) Tamoxifen after adjuvant chemotherapy for premenopausal women with lymph node-positive breast cancer: International Breast Cancer Study Group Trial 13-93. J Clin Oncol 24(9):1332-41

14. Hutchins LF, Green SJ, Ravdin PM, et al (2005) Randomized, controlled trial of cyclophosphamide, methotrexate, and fluorouracil versus cyclophosphamide, doxorubicin, and fluorouracil with and without 
tamoxifen for high-risk, node-negative breast cancer: treatment results of Intergroup Protocol INT-0102. J Clin Oncol 23(33):8313-21

15. Chia S, Gradishar W (2008) Fulvestrant: expanding the endocrine treatment options for patients with hormone receptor-positive advanced breast cancer. Breast 17 Suppl 3:16-21

16. Harvey JM, Clark GM, Osborne CK, et al (1999) Estrogen receptor status by immunohistochemistry is superior to the ligand-binding assay for predicting response to adjuvant endocrine therapy in breast cancer. $\mathrm{J}$ Clin Oncol 17(5):1474-81

17. Elledge RM, Green S, Pugh R, et al (2000) Estrogen receptor (ER) and progesterone receptor $(\mathrm{PgR})$, by ligand-binding assay compared with $\mathrm{ER}$, $\mathrm{PgR}$ and $\mathrm{pS2}$, by immuno-histochemistry in predicting response to tamoxifen in metastatic breast cancer: a Southwest Oncology Group Study. Int J Cancer 89(2):111-7

18. Andre F, Broglio K, Roche H, et al (2008) Estrogen receptor expression and efficacy of docetaxel-containing adjuvant chemotherapy in patients with node-positive breast cancer: results from a pooled analysis. J Clin Oncol 26(16):2636-43

19. Reiner A, Spona J, Reiner G, et al (1986) Estrogen receptor analysis on biopsies and fine-needle aspirates from human breast carcinoma. Correlation of biochemical and immunohistochemical methods using monoclonal antireceptor antibodies. Am J Pathol 125: 443-449

20. Hammond M, Hayes D, Dowsett M, et al (2010) American Society of Clinical Oncology/College of American Pathologists Guideline Recommendations for Immunohistochemical Testing of Estrogen and 
Progesterone Receptors in Breast Cancer. J Clin Oncol 28(16): 27842795

21. Allred DC, Harvey JM, Berardo M, et al (1998) Prognostic and predictive factors in breast cancer by immunohistochemical analysis. Mod Pathol 11: $155-68$

22. Remmele W, Stegner HE (1987) Vorschlag zur einheitlichen Definierung eines immunreaktiven Scores (IRS) für den immunhistochemischen Östrogenrezeptornachweis (ER-ICA) im Mammakarzinomgewebe. Pathologe 8:138-140

23. Remmele W (1997) Pathologie Bd 4. Weibliches Genitale; Mamma; Pathologie der Schwangerschaft, der Plazenta und des Neugeborenen; Infektionskrankheiten des Fetus und des Neugeborenen (ed 2) Springer Verlag Berlin Heidelberg New York

24. Viale G, Regan MM, Maiorano E, et al (2007) Prognostic and predictive value of centrally reviewed expression of estrogen and progesterone receptors in a randomized trial comparing letrozole and tamoxifen adjuvant therapy for postmenopausal early breast cancer: BIG 1-98. J Clin Oncol 25(25):3846-52

25. Dowsett M, Allred C, Knox J, et al (2008) Relationship between quantitative estrogen and progesterone receptor expression and human epidermal growth factor receptor 2 (HER-2) status with recurrence in the Arimidex, Tamoxifen, Alone or in Combination trial. J Clin Oncol 26(7):1059-65

26. Paik S, Shak S, Tang G, et al (2005) Expression of the 21 genes in the Recurrence Score assay and tamoxifen clinical benefit in the NSABP study B-14 of node negative, estrogen receptor positive breast cancer. J 
Clin Oncol 2005 ASCO Annual Meeting Proceedings. 23(16S), (suppl; abstr 510)

27. Fisher B, Jeong JH, Bryant J, et al (2004) National Surgical Adjuvant Breast and Bowel Project randomised clinical trials. Treatment of lymphnode-negative, oestrogen-receptor-positive breast cancer: long-term findings from National Surgical Adjuvant Breast and Bowel Project randomised clinical trials. Lancet 364(9437):858-68

28. Mazouni C, Bonnier P, Goubar A, et al (2010) Is quantitative oestrogen receptor expression useful in the evaluation of the clinical prognosis? Analysis of a homogeneous series of 797 patients with prospective determination of the ER status using simultaneous EIA and IHC, Eur $\mathrm{J}$ Cancer 46: 2716-2715

29. Henriksen KL, Rasmussen BB, Lykkesfeldt AE, et al (2009) An ER activity profile including ER, PR, Bcl-2 and IGF-IR may have potential as selection criterion for letrozole or tamoxifen treatment of patients with advanced breast cancer. Acta Oncol 48(4):522-31

30. De Laurentiis M, Cancello G, D'Agostino D, et al (2008) Taxane-based combinations as adjuvant chemotherapy of early breast cancer: a metaanalysis of randomized trials. J Clin Oncol 26(1):44-53

31. Bedard PL, Di Leo A, Piccart-Gebhart MJ (2010) Taxanes: optimizing adjuvant chemotherapy for early-stage breast cancer. Nature Rev Clin Oncol 7: 22-36

32. Berry DA, Cirrincione C, Henderson IC, Citron ML, et al (2006) Estrogenreceptor status and outcomes of modern chemotherapy for patients with node-positive breast cancer. J Amer Med Assoc 295(14):1658-67 
33. Green MC, Buzdar AU, Smith T, et al (2005) Weekly paclitaxel improves pathologic complete remission in operable breast cancer when compared with paclitaxel once every 3 weeks. J Clin Oncol 23:5983- 5992

34. Mazouni C, Kau SW, Frye D, et al (2007) Inclusion of taxanes, particularly weekly paclitaxel, in preoperative chemotherapy improves pathologic complete response rate in estrogen receptor-positive breast cancers. Ann Oncol 18:874-880

35. von Minckwitz G, Blohmer JU, Raab G, et al (2005) German Breast Group: In vivo chemosensitivity adapted preoperative chemotherapy in patients with early-stage breast cancer-The GEPARTRIO pilot study. Ann Oncol 16:56-63

36. Sotiriou C, Pusztai L (2009) Gene-expression signatures in breast cancer. N Engl J Med 360(8):790-800

37. Pusztai L (2006) Chips to bedside: incorporation of microarray data into clinical practice. Clin Cancer Res 15;12(24):7209-14

38. Mook S, Schmidt MK, Viale G, et al (2009) The 70-gene prognosissignature predicts disease outcome in breast cancer patients with 1-3 positive lymph nodes in an independent validation study. Breast Cancer Res Treat. 116(2):295-302.

39. Bueno-de-Mesquita JM, Linn SC, Keijzer R, et al (2009) Validation of 70gene prognosis signature in node-negative breast cancer. Breast Cancer Res Treat. 117(3):483-95

40. Paik S, Shak S, Tang G, et al (2004) A multigene assay to predict recurrence of tamoxifen-treated, node-negative breast cancer. $\mathrm{N}$ Engl $\mathrm{J}$ Med 351(27):2817-26 
41. Paik S, Tang G, Shak S, et al (2006) Gene expression and benefit of chemotherapy in women with node-negative, estrogen receptor-positive breast cancer. J Clin Oncol 24(23):3726-34

42. Albain KS, Barlow WE, Shak S, et al (2010) Breast Cancer Intergroup of North America. Prognostic and predictive value of the 21-gene recurrence score assay in postmenopausal women with node-positive, oestrogen-receptor-positive breast cancer on chemotherapy: a retrospective analysis of a randomised trial. Lancet Oncol 11(1):55-65

43. Goldstein LJ, Gray R, Badve S, et al (2008) Prognostic utility of the 21gene assay in hormone receptor-positive operable breast cancer compared with classical clinicopathologic features. J Clin Oncol 26(25):4063-71

44. Knauer M, Mook S, Rutgers EJ, et al (2010) The predictive value of the 70-gene signature for adjuvant chemotherapy in early breast cancer. Breast Cancer Res Treat. 120(3):655-61

45. Tang G, Cuzick J, Wale C, et al (2010) Recurrence risk of node-negative and ER-positive early-stage breast cancer patients by combining recurrence score, pathologic, and clinical information: A meta-analysis approach. J Clin Oncol 28:15s, (suppl; abstr 509)

46. Hauck W, Anderson S, Marcus S (1998) Should We Adjust for Covariates in Nonlinear Regression Analyses of Randomized Trials? Control Clin Trials 19(3):249-56

47. Berger ML, Mamdani M, Atkins D, et al (2009) Good research practices for comparative effectiveness research: defining, reporting and interpreting non-randomized studies of treatment effects using secondary 
data sources: The ISPOR good research practices for retrospective database analysis task force report-Part I. Value Health 12(8):1044-52

48. Cox E, Martin BC, Van Staa T, et al (2009) Good research practices for comparative effectiveness research: approaches to mitigate bias and confounding in the design of non-randomized studies of treatment effects using secondary data sources: The ISPOR good research practices for retrospective database analysis task force-Part II. Value Health 12(8):1053-61 


\section{Figure legends}

Fig. 1: Recurrence free survival stratified for ER IRS groups.

Fig. 2: Recurrence free survival of patients with high expression of ER stratified for endocrine treatment, chemoendocrine treatment, and chemotherapy without (A) and with adjustment (B) to prognostic factors (NPI, menopausal status, and HER2/neu).

Fig. 3: Recurrence free survival of patients with high expression of ER stratified for Nottingham prognostic index (NPI) (A). Recurrence free survival of high-risk (NPI) patients with high expression of ER stratified for endocrine treatment, chemoendocrine treatment, and chemotherapy and adjusted to HER2/neu (B).

Fig. 4: Recurrence free survival of patients with high expression of ER stratified for endocrine treatment, and taxane-endocrine therapy, adjusted to NPI, menopausal status, and HER2/neu. 
Tables

Table 1: Calculation of IRS: Proportion and intensity score

\begin{tabular}{|l|l|l|}
\hline proportion & $\begin{array}{l}\text { staining } \\
\text { intensity }\end{array}$ & $\begin{array}{l}\text { proportion } \\
\text { score (PS)/ } \\
\text { intensity score } \\
\text { (IS) }\end{array}$ \\
\hline $0 \%$ & negative & $\mathbf{0}$ \\
\hline$<10 \%$ & weak & $\mathbf{1}$ \\
\hline $10 \%-50 \%$ & intermediate & $\mathbf{2}$ \\
\hline $51 \%-80 \%$ & strong & $\mathbf{3}$ \\
\hline$>80 \%$ & - & $\mathbf{4}$ \\
\hline Interpretation (PS * IS) & \\
\hline $0-1$ & negative \\
\hline $2-3$ & positive: weak \\
\hline $4-8$ & positive: moderate \\
\hline $9-12$ & positive: strong \\
\hline
\end{tabular}


Table 2: Baseline characteristics

\begin{tabular}{|c|c|c|c|c|c|c|}
\hline & & \multirow[b]{2}{*}{ Total } & \multicolumn{3}{|c|}{ ER-Expression } & \multirow[t]{2}{*}{$\begin{array}{c}\text { Chi- } \\
\text { Square }\end{array}$} \\
\hline & & & $\begin{array}{c}\text { negative } \\
\qquad(0-1)\end{array}$ & $\begin{array}{c}\begin{array}{c}\text { weak or } \\
\text { moderate }\end{array} \\
(2-8)\end{array}$ & $\begin{array}{l}\text { high } \\
(9-12)\end{array}$ & \\
\hline & & $\begin{array}{l}\mathrm{N} \\
(\%)\end{array}$ & $\begin{array}{l}\mathrm{N} \\
(\%)\end{array}$ & $\begin{array}{l}\mathrm{N} \\
(\%)\end{array}$ & $\begin{array}{l}\mathrm{N} \\
(\%)\end{array}$ & (Sig) \\
\hline Patients & & $3971(100)$ & $1079(27.2)$ & $1297(32.6)$ & 1595 (40.2) & \\
\hline \multirow[t]{2}{*}{ Age } & $\begin{array}{l}\text { Median } \\
\text { (Mean; std) }\end{array}$ & $\begin{array}{r}61 \\
(60.5 ; 13.1)\end{array}$ & $\begin{array}{r}57 \\
(57.1 ; 13.4) \\
\end{array}$ & $\begin{array}{r}58 \\
(58.3 ; 12.7) \\
\end{array}$ & $\begin{array}{r}65 \\
(64.6 ; 12.1)\end{array}$ & \\
\hline & Range & $22-101$ & $28-95$ & $24-101$ & $22-97$ & \\
\hline \multirow[t]{4}{*}{ Age categories } & $<35$ & $59(1.5)$ & $24(2.2)$ & $22(1.7)$ & $13(0.8)$ & \multirow{4}{*}{$<0.001$} \\
\hline & $35-55$ & 1365 (34.4) & $483(44.8)$ & $543(41.9)$ & 339 (21.3) & \\
\hline & $56-75$ & 1975 (49.7) & 456 (42.3) & $598(46.1)$ & $921(57.7)$ & \\
\hline & $>75$ & $572(14.4)$ & $116(10.8)$ & $134(10.3)$ & $322(20.2)$ & \\
\hline \multirow{3}{*}{$\begin{array}{l}\text { Menopausal } \\
\text { status }\end{array}$} & unknown & $185(4.7)$ & $55(5.1)$ & $79(6.1)$ & $51(3.2)$ & \multirow{3}{*}{$<0.001$} \\
\hline & premenopausal & $903(22.7)$ & 344 (31.9) & $369(28.5)$ & $190(11.9)$ & \\
\hline & postmenopausal & $2883(72.6)$ & $680(63.0)$ & 849 (65.5) & 1354 (84.9) & \\
\hline \multirow[t]{4}{*}{ Tumor size } & T1 & $2024(52.8)$ & $480(46.6)$ & $705(56.0)$ & $839(54.4)$ & \multirow{4}{*}{$<0.001$} \\
\hline & $\mathrm{T} 2$ & 1377 (36.0) & $433(42.0)$ & $411(32.7)$ & $533(34.6)$ & \\
\hline & T3 & $178(4.6)$ & $60(5.8)$ & $50(4.0)$ & $68(4.4)$ & \\
\hline & $\mathrm{T} 4$ & $251(6.6)$ & $57(5.5)$ & $92(7.3)$ & $102(6.6)$ & \\
\hline \multirow[t]{5}{*}{ Nodal status } & unknown & $79(2.0)$ & $24(2.2)$ & $20(1.5)$ & $35(2.2)$ & \multirow{5}{*}{0.008} \\
\hline & nodal negative & $2264(57.3)$ & 629 (58.5) & $735(56.8)$ & $900(56.8)$ & \\
\hline & $1-3$ & $882(22.3)$ & 201 (18.7) & $310(24.0)$ & $371(23.4)$ & \\
\hline & $4-10$ & $486(12.3)$ & $136(12.7)$ & $150(11.6)$ & $200(12.6)$ & \\
\hline & $>10$ & $242(6.1)$ & $85(7.9)$ & $78(6.0)$ & $79(5.0)$ & \\
\hline \multirow[t]{4}{*}{ Grading } & unknown & $45(1.1)$ & $22(2.0)$ & $15(1.2)$ & $8(0.5)$ & \multirow{4}{*}{$<0.001$} \\
\hline & 1 & $268(6.7)$ & $40(3.7)$ & $111(8.6)$ & $117(7.3)$ & \\
\hline & 2 & 2271 (57.2) & $336(31.1)$ & $814(62.8)$ & 1121 (70.3) & \\
\hline & 3 & 1387 (34.9) & $681(63.1)$ & $357(27.5)$ & $349(21.9)$ & \\
\hline HER2/neu & unknown & $614(15.5)$ & 175(16.2) & $220(17.0)$ & $219(13.7)$ & \\
\hline
\end{tabular}




\begin{tabular}{|c|c|c|c|c|c|c|}
\hline \multirow[t]{2}{*}{ status } & negative & 2809 (70.7) & $627(58.1)$ & $934(72.0)$ & 1248 (78.2) & \multirow[t]{2}{*}{$<0.001$} \\
\hline & positive & $548(13.8)$ & $277(25.7)$ & $143(11.0)$ & $128(8.0)$ & \\
\hline \multirow[t]{4}{*}{$\overline{N P I}$} & missing & $141(3.6)$ & $49(4.5)$ & $39(3.0)$ & $53(3.3)$ & \multirow{4}{*}{$<0.001$} \\
\hline & low & $1193(30.0)$ & $180(16.7)$ & $447(34.5)$ & $566(35.5)$ & \\
\hline & intermediate & $1819(45.8)$ & $565(52.4)$ & $567(43.7)$ & $687(43.1)$ & \\
\hline & high & $818(20.6)$ & $285(26.4)$ & $244(18.8)$ & $289(18.1)$ & \\
\hline \multirow{4}{*}{$\begin{array}{l}\text { Systemic } \\
\text { Therapy }\end{array}$} & Endocrine therapy & $1550(39.0)$ & $80(7.4)$ & $578(44.6)$ & $892(55.9)$ & \multirow{4}{*}{$<0.001$} \\
\hline & Chemotherapy & $423(10.7)$ & $300(27.8)$ & $72(5.6)$ & $51(3.2)$ & \\
\hline & $\begin{array}{l}\text { Endocrine and } \\
\text { chemotherapy }\end{array}$ & $913(23.0)$ & $107(9.9)$ & $423(32.6)$ & $383(24.0)$ & \\
\hline & others & 1085 (27.3) & $592(54.9)$ & $224(17.3)$ & $269(16.9)$ & \\
\hline \multirow{4}{*}{ Chemotherapy } & All & $\begin{array}{r}1844 \\
(100.0)\end{array}$ & $666(36.1)$ & $581(31.5)$ & $597(32.4)$ & \multirow{4}{*}{$<0.001$} \\
\hline & CMF & 467 (25.3) & $196(26.1)$ & $151(25.9)$ & $120(23.5)$ & \\
\hline & $\begin{array}{l}\text { Taxane-containing } \\
\text { therapy }\end{array}$ & $481(26.1)$ & $169(22.5)$ & $163(28.0)$ & $149(29.1)$ & \\
\hline & $\begin{array}{l}\text { Anthracycline- } \\
\text { containing therapy }\end{array}$ & $896(48.6)$ & $386(51.4)$ & $268(46.1)$ & $242(47.4)$ & \\
\hline
\end{tabular}




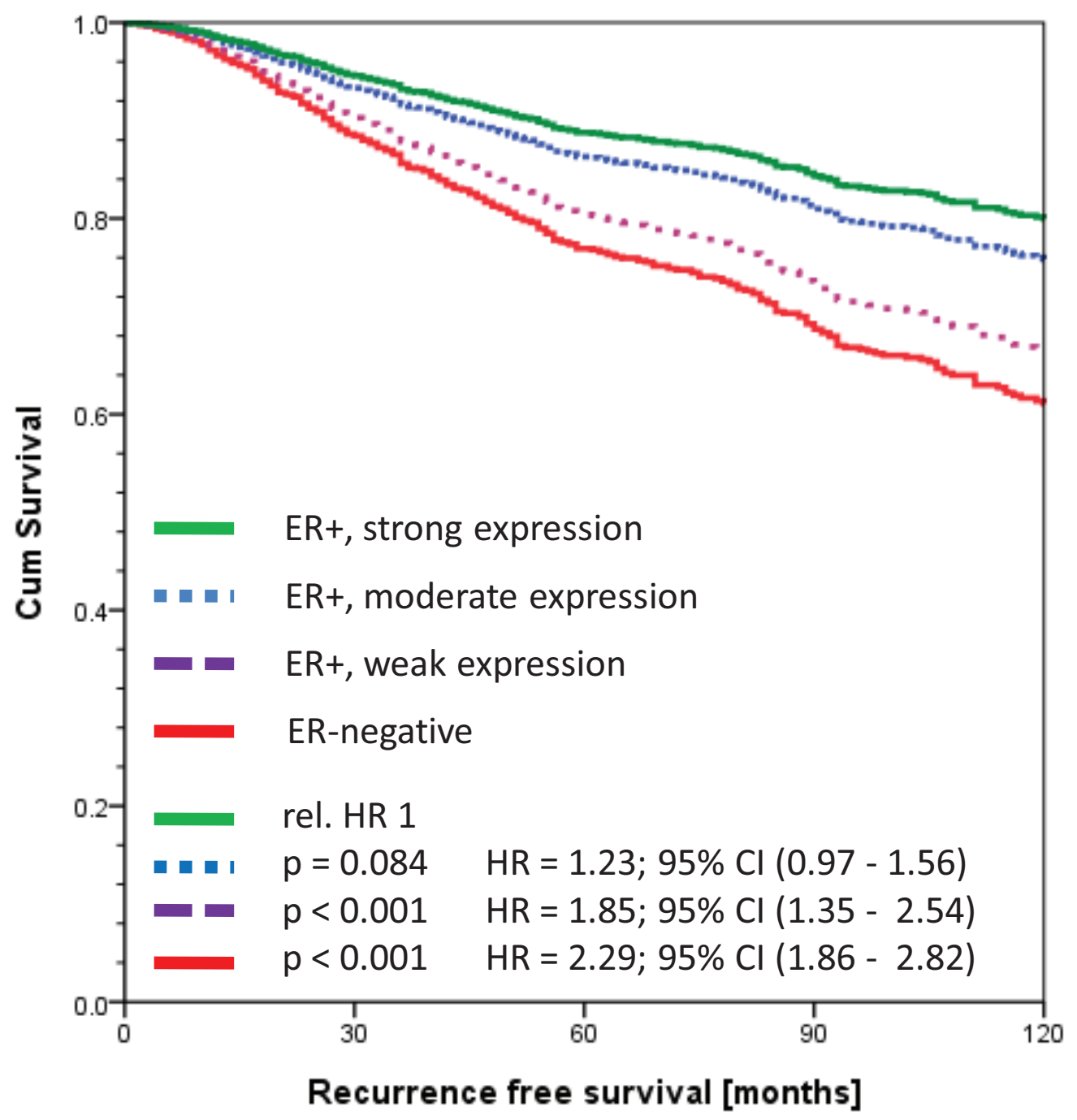




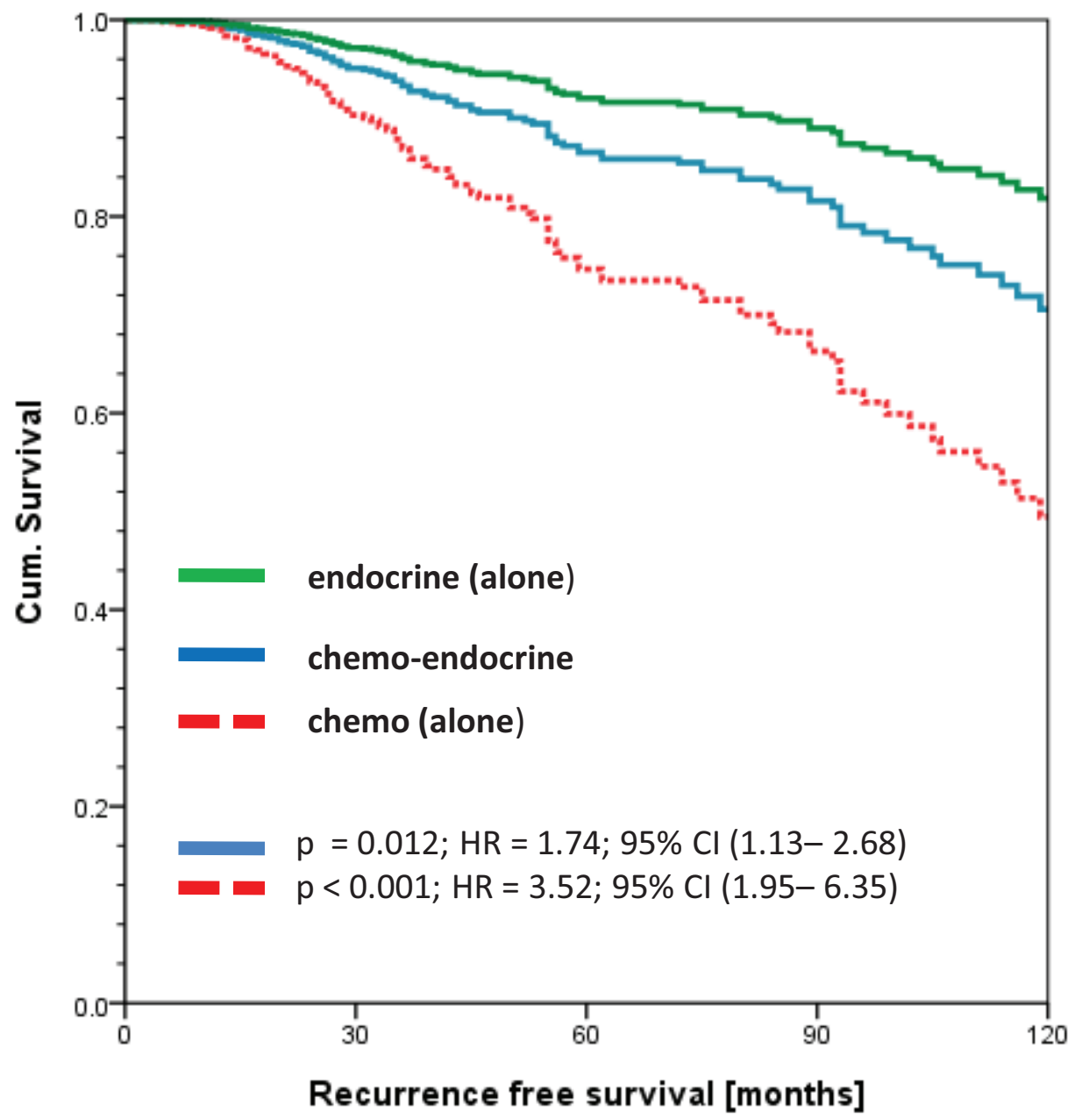




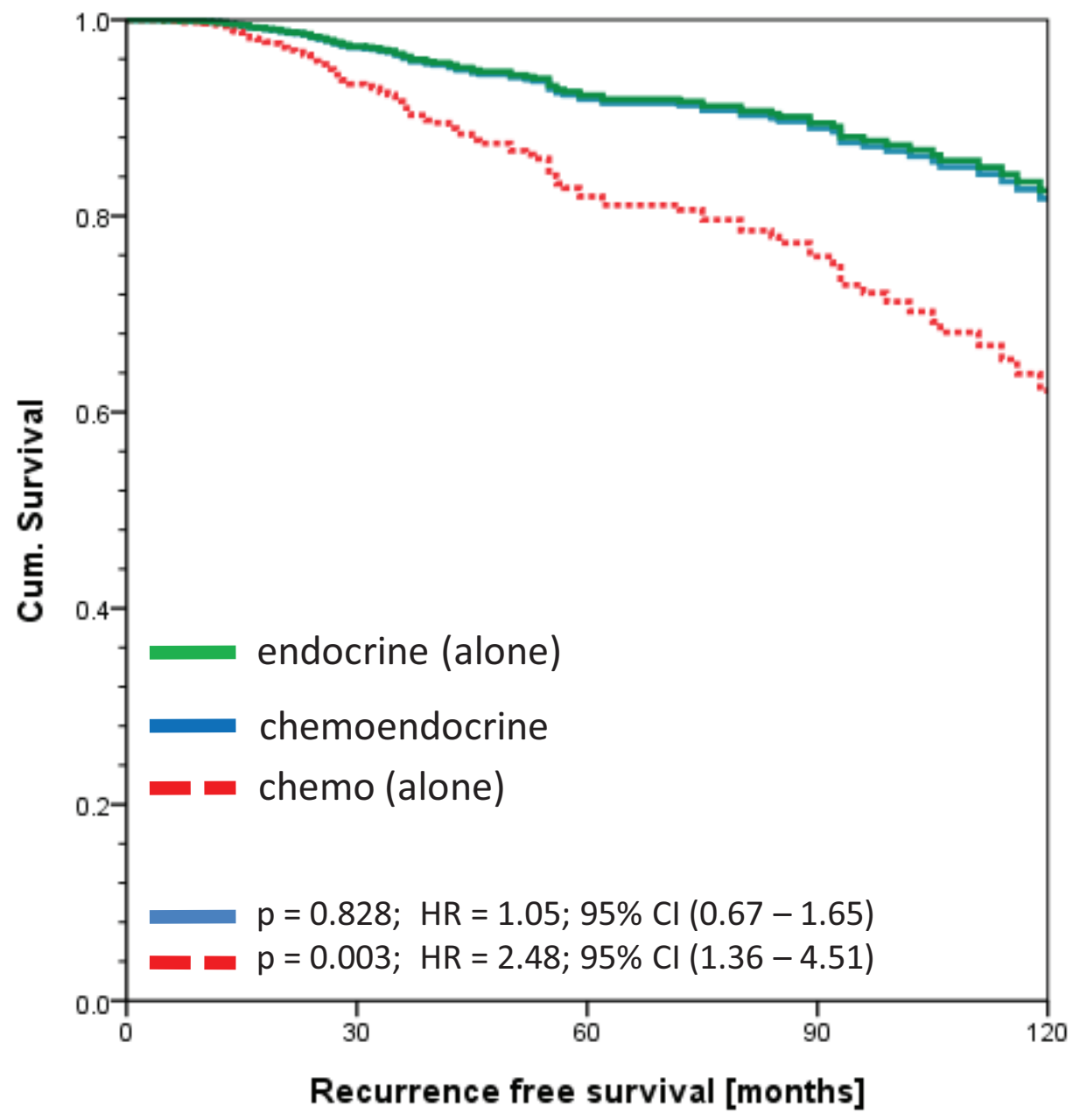




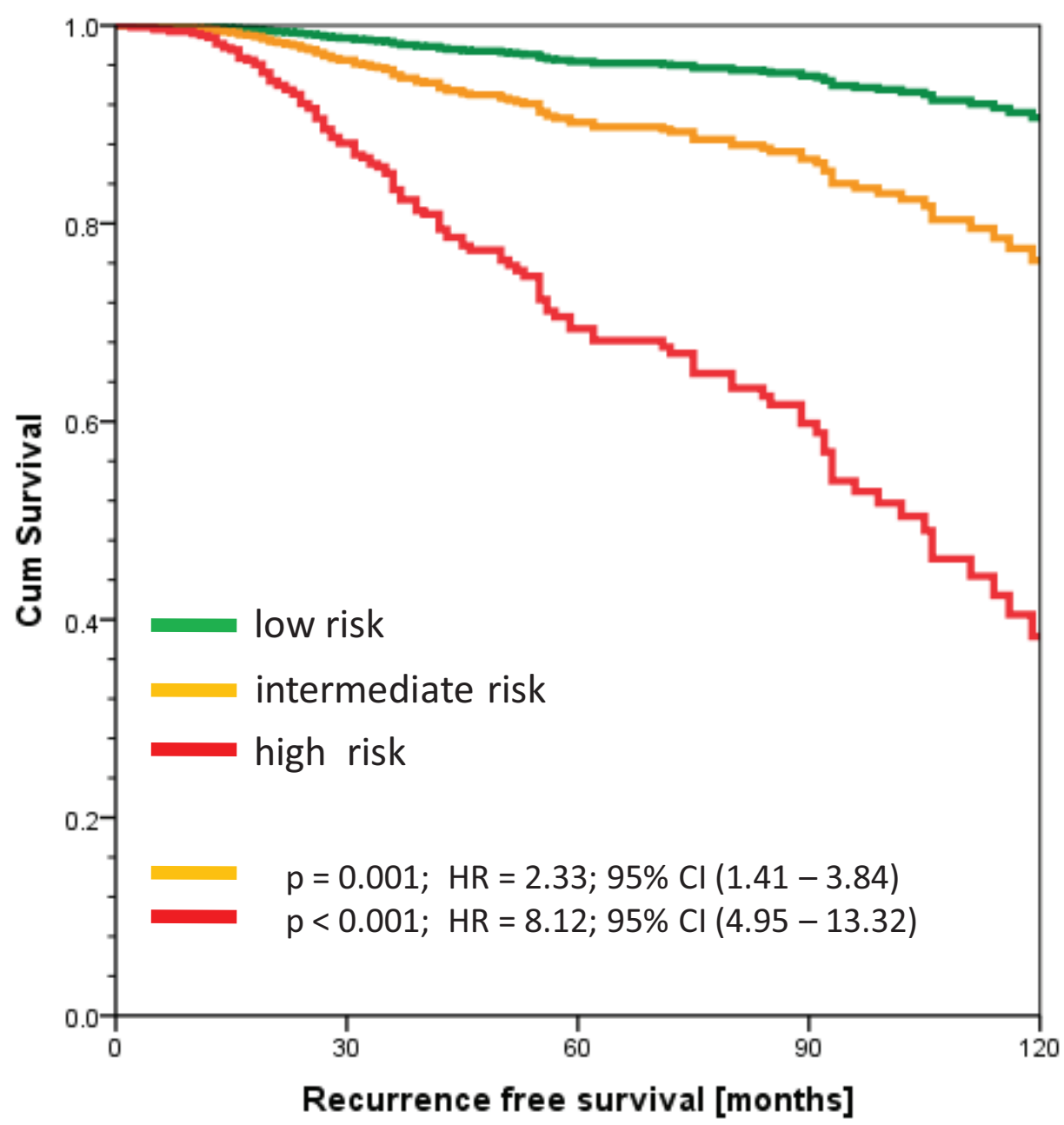




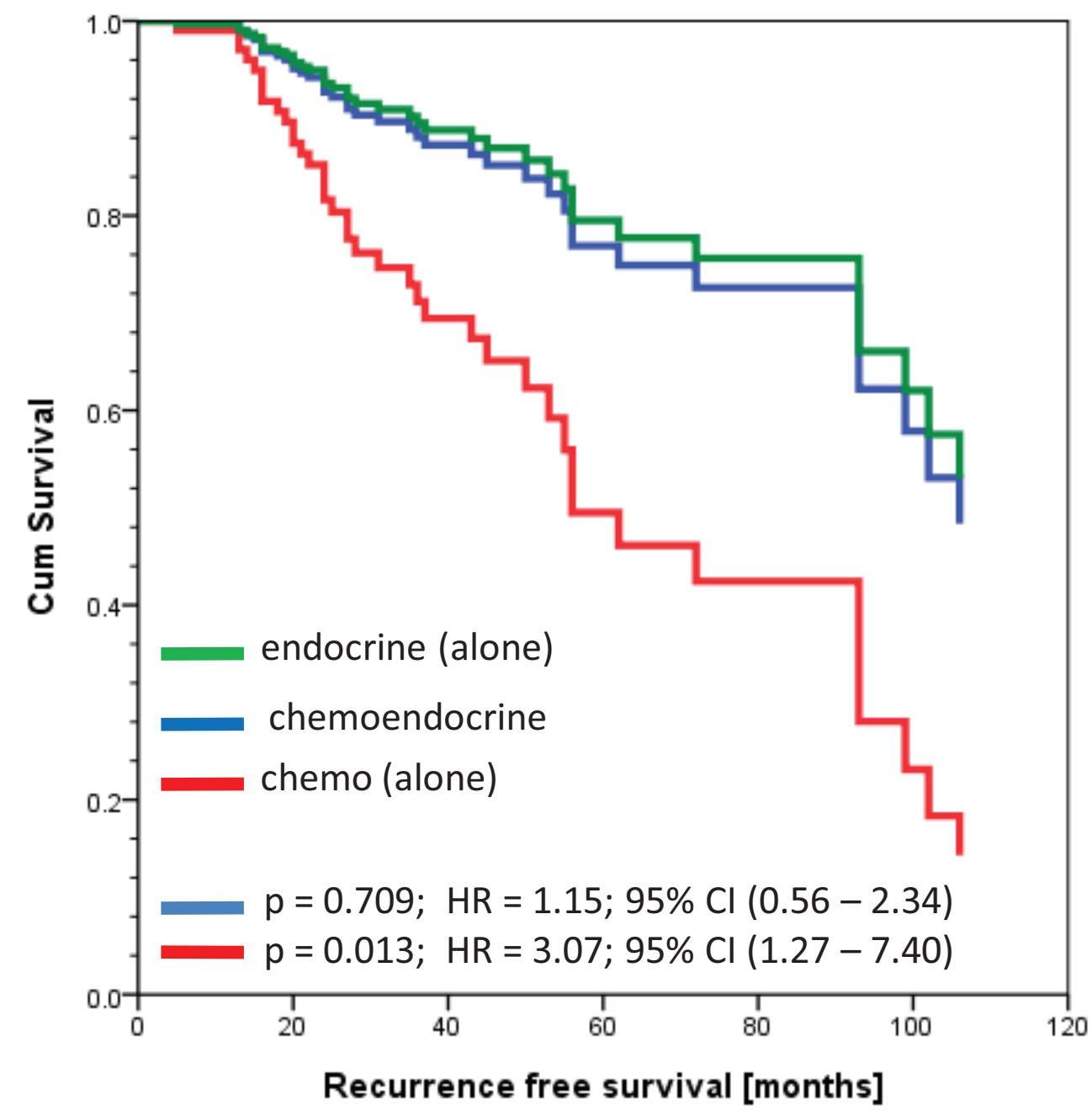




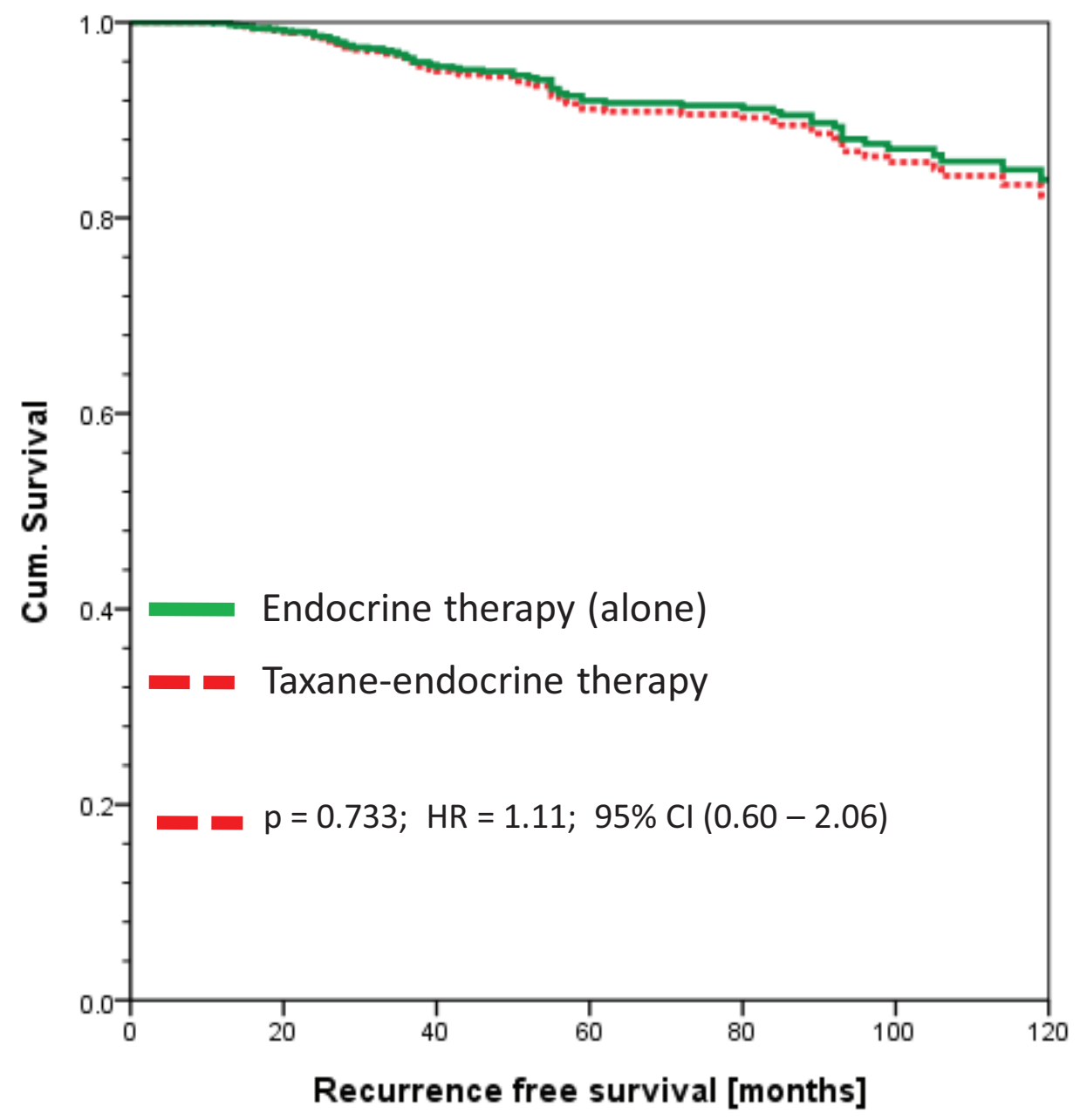

